\title{
A ENFERMAGEM E PUÉRPERAS PRIMIGESTAS: DESVENDANDO O PROCESSO DE TRANSIÇÃO AO PAPEL MATERNO*
}

\author{
Alexandra Maria Alves ${ }^{1}$, Cristhiane da Silva Ferreira Gonçalves ${ }^{1}$, Maria Aparecida Martins ${ }^{1}$, Sueli Terezinha da Silva ${ }^{1}$, \\ Tânia Cristina Auwerter ${ }^{1}$, Ivete Palmira Sanson Zagonel ${ }^{2}$
}

RESUMO: Estudo que tem como objeto o processo de transição ao papel materno de puérperas primigestas. Utiliza a metodologia qualitativa e o método exploratório-descritivo. Tem como objetivos desvelar as percepções sobre a transição ao papel materno entre puérperas primigestas e delinear estratégias de cuidado de enfermagem transicional que facilitem o alcance ao papel materno. Os sujeitos foram onze puérperas primigestas no período pós-parto mediato, em alojamento conjunto de maternidade filantrópica de Curitiba. Utilizou-se a entrevista semi-estruturada. A análise das informações seguiu as etapas de análise de conteúdo temática de Bardin (1991). Foram apreendidas quatro Unidades de Contexto: Gravidez: uma trajetória de aceitação e expectativa; Parto: concluindo uma caminhada; O período puerperal: enfrentando novos papéis; Ações da enfermagem junto às puérperas. É possível compreender a vivência da mulher rumo ao papel materno, seus sentimentos, realizações, dificuldades, mudanças impostas pela chegada do bebê e o cuidado de enfermagem nessa fase de transição.

PALAVRAS-CHAVE: Cuidados de enfermagem; Período pós-parto; Enfermagem obstétrica.

\section{NURSING AND PUERPERAL PRIMIPARAS: UNVEILING THE PROCESS OF TRANSITION TO MATERNAL ROLE}

\begin{abstract}
Study that objectifies the process of transition to maternal role of puerperal primiparas. It uses the qualitative methodology and the exploratory-descriptive method. It aims to disclose the puerperal primiparas' perceptions on the transition to maternal role and to delineate strategies of transitional nursing care that facilitate the achievement of maternal role. The subjects were eleven puerperal primiparas in the period immediately after childbirth, in a rooming-in facility at a philanthropic maternity hospital in Curitiba City/ Brazil. It was used a semi-structured interview. Information analysis followed the stages of Bardin's thematic analysis of content (1991). Four Context Units were apprehended: Pregnancy: a trajectory of acceptance and expectation; Childbirth: a concluded journey; The puerperal period: facing new roles; Nursing Actions for the puerperal primiparas. It is possible to understand the women's lived experience to maternal role, their feelings, accomplishments, difficulties, changes imposed by the baby's arrival and nursing care in this transitional phase.
\end{abstract}

KEYWORDS: Nursing care; Puerperal period; Obstetric nursing.

\section{LA ENFERMERIA Y PUÉRPERAS PRIMERIZAS: DESCUBRIENDO EL PROCESO DE TRANSICION AL PAPEL MATERNO}

RESUMEN: Estudio que tiene como objetivo, el proceso de transición al papel materno de puérperas primerizas. Utiliza la metodología cualitativa y el método exploratorio descriptivo. Tiene como objetivos revelar las percepciones sobre la transición al papel materno entre puérperas primerizas y delinear estrategias de cuidado en enfermería transicional que faciliten el alcance al papel materno. Los sujetos fueron once puérperas primerizas en el período post parto inmediato, en alojamiento conjunto de la maternidad filantrópica de Curitiba. Se utilizó la entrevista semi estructurada. El análisis de las informaciones siguió las etapas del análisis de contenido temático de Bardin (1991). Fueron aprendidas cuatro Unidades de Contexto: Embarazo: una trayectoria de aceptación y expectativa; Parto: concluyendo una caminada; El período puerperal: enfrentando nuevos papeles; Acciones de la enfermería junto a las puérperas. Es posible comprender la vivencia de la mujer rumbo al papel materno, sus sentimientos, realizaciones, dificultades, cambios impuestos por la llegada del bebé y el cuidado de la enfermería en esa etapa de transición.

PALABRAS CLAVE: Atención de enfermería; Periodo de posparto; Enfermería obstétrica.

\footnotetext{
"Trabalho resultante da Disciplina Momento Integrador V e VI do Curso de Enfermagem do Instituto de Ensino Superior Pequeno Príncipe - IESPP. ${ }^{1}$ Acadêmicas do $8^{\circ}$ período do Curso de Enfermagem do IESPP.

${ }^{2}$ Enfermeira. Doutora em Enfermagem. Coordenadora do Curso de Enfermagem do IESPP e do Núcleo de Estudos, Pesquisa e Extensão em Enfermagem - NEPEE. Orientadora do trabalho.
}

\section{Autor correspondente:}

Alexandra Maria Alves

Rua Adélio Ferreira, 434 - 83.430-000 - Campina Grande do Sul-PR

Recebido: 30/08/07

E-mail: aalelinda@yahoo.com.br 


\section{INTRODUÇÃO}

A expectativa de ser mãe, de vivenciar por nove meses uma nova vida dentro de si, o convívio diário com este ser que ainda não conhece, mas que desde o momento da concepção já faz parte de sua vida e de todos que a cercam são motivos de alegria, satisfação e prazer para a futura mãe. Porém, ela convive ao mesmo tempo com a ansiedade, incerteza, insegurança, sentimentos que permeiam o desenvolvimento da gravidez, o momento do nascimento e o período pósparto. Esses são aspectos que devem ser considerados ao se buscar compreender como as mulheres puérperas primigestas percebem essas significativas mobilizações. Sentimentos ambivalentes acompanham o cotidiano da gestante até o momento do parto. Assim, o processo de nascimento torna-se um momento singular e importante pelas modificações a que a gestante esteve exposta e pelas novas rotinas que o nascimento demanda. Esse estudo aborda a puérpera primigesta, por entender que pela primeira vez ela vai sentir, conhecer e conviver com a nova vida que se inicia.

O período puerperal é cercado de intensas mobilizações, pois a mulher que agora é mãe, por vezes não entende a transição pela qual está passando. Transição entendida como a passagem, mudança, mobilização, modificação de um estado, condição ou circunstância para outra. Pode ocorrer de forma intencional ou de forma inesperada. A transição à maternidade ou papel materno caracteriza-se como transição familiar, pois o impacto das experiências tem sentido para todos os membros da família. As necessidades da família que está gerando o filho devem ser reconhecidas pelos enfermeiros, compreendendo os efeitos da concepção sobre cada membro do núcleo familiar exposto à experiência.

Essa transição ao papel materno não é fácil, pois a mulher perde a simbologia da 'barriga' e o que estava dentro de si, nasce o bebê, que agora assume forma concreta em seus braços. Esse fato desencadeia sentimentos, emoções, ações e reações que, muitas vezes, a puérpera primigesta não está preparada para enfrentar e conseqüentemente, se adaptar ao novo papel. Esse preparo para o enfrentamento do papel materno é necessário iniciar ainda no pré-natal, pois a gestante terá um tempo cronológico de nove meses para interiorizar, assimilar a idéia, a perspectiva de ser mãe, tempo esse que não corresponde necessariamente ao tempo cronológico de vivência dessa passagem de papéis, mas ao tempo que cada uma necessita para alcançar o papel materno.
A chegada de um filho promove, de forma direta e indireta, mudanças na rotina familiar para receber o novo membro, criando diversas expectativas, desse momento cercado de incertezas, medos e inseguranças. A notícia da chegada de um filho gera na família uma diversidade de emoções; antes mesmo do bebê vir ao mundo, os pais têm inúmeras preocupações $^{(1)}$. A mulher-mãe se vê cercada de fantasia e realidade, alterações e mudanças no seu diaa-dia de trabalhadora, esposa e, agora, mãe. Com uma nova vida no seio familiar, a mulher muda seu estilo de vida para se adequar também às necessidades do bebê, as quais podem trazer dificuldades no relacionamento familiar e social.

Com a transição ao papel materno a mulher vivencia uma mudança de um estado para outro, inicia um novo ciclo de desenvolvimento na organização do seu cotidiano, no cuidado com o novo membro da família exigindo a continuidade de suas relações com o entorno que cerca sua família e a sociedade ${ }^{(2)}$. As demandas do cuidado de um bebê são grandes e a mulher tem que estar preparada para superar essa fase de mudanças fisiológicas marcantes, choro, irritação, cólica do bebê, aleitamento, afazeres domésticos e demais ações que necessitam ser revistas e reajustadas.

Tornar-se mãe é um processo de intensa transformação existencial na vida da mulher e é nas primeiras semanas após o parto que as mulheres enfrentam os maiores desafios, mesmo já tendo planejado e aceito a função materna. No entanto, as situações, muitas vezes imprevisíveis, que envolvem a relação mãe e filho, não se esgotam com o final do puerpério; elas fazem parte da relação e, por isso, perduram por toda a vida ${ }^{(3)}$.

$\mathrm{O}$ início da adaptação à maternidade suscita nos pais sentimentos de incapacidade e confusão frente às novas demandas, levando a buscar apoio um no outro $^{(4)}$. As mães ocupadas com o cuidado ao filho nem sempre conseguem oferecer o apoio necessário ao pai, o qual sente-se privado de suporte. O despreparo em lidar com as emoções e cuidados exigidos neste período conduz à inadequação no desempenho de papel, porém, à medida que os pais vivenciam esta experiência a inabilidade vai desaparecendo e emergem sentimentos de companheirismo, compartilhamento de situações e entrega aos papéis exteriorizados pelo amor, carinho, afeto e solidariedade entre os pais.

A partir dessa contextualização surgem algumas inquietações: a mulher que passa a ser mãe vai conseguir cuidar do seu bebê? A puérpera conseguirá desempenhar 
seu papel de esposa, dona de casa, trabalhadora, às vezes de estudante, e ainda ter tempo para seu próprio cuidado? Como enfrenta e se adapta aos novos papéis? Como o entorno familiar e social são mobilizados com a chegada do filho? Estas questões auxiliaram a delimitar a questão norteadora: como a mulher puérpera primigesta percebe a transição ao papel materno com as mudanças impostas pelo nascimento do filho? Para responder a esta questão delineamos os objetivos: desvelar as percepções sobre a transição ao papel materno com puérperas primigestas no período pósparto mediato e delinear estratégias de cuidado de enfermagem que facilitem o alcance do papel materno.

\section{TRAJETÓRIA METODOLÓGICA}

A metodologia do estudo é qualitativa, por meio do método exploratório-descritivo. A pesquisa qualitativa é aquela em que o pesquisador tem como alvo a melhor compreensão do comportamento e da experiência humana, em que procura entender o processo pelo qual as pessoas constroem significados e descrevem o que são esses significados ${ }^{(5)}$.

Os sujeitos que participaram do estudo foram onze puérperas primigestas no período pós-parto mediato, enquanto permaneciam na unidade de alojamento conjunto. A escolha dos sujeitos foi diretamente relacionada aos objetivos do estudo, tendo como critérios de inclusão ser primigesta e estar vivenciando o período puerperal mediato. A opção por primigestas no período puerperal deu-se por elas estarem vivenciando pela primeira vez o papel materno, pois ainda desconhecem as emoções e surpresas, felicidade e até as frustrações desse período; e também por ser um momento impar, novo, cercado de crenças culturais, expectativas e que possibilita melhor compreensão das mudanças para a apropriação do papel materno.

O local em que se realizou o estudo foi em maternidade filantrópica de Curitiba, com duas enfermarias de alojamento conjunto. A maternidade realiza 97\% dos seus atendimentos pelo SUS (Sistema Único de Saúde) e 3\% por convênios. Tem como missão e valores a humanização no atendimento ao público. A maternidade tem uma média de 480 nascimentos e 44 atendimentos de recém-nascido na UTI Neonatal ao mês. É portadora do título Hospital Amigo da Criança conquistado em 1998.

A entrada no campo deu-se após a aprovação do estudo pelo Comitê de Ética e autorização da instituição, a qual foi facilitada, uma vez que as autoras do trabalho já haviam realizado aulas práticas curriculares na instituição.

Para a coleta das informações utilizamos a entrevista semi-estruturada aplicada diretamente pelos pesquisadores, que permitiu buscar o significado da vivência e interpretar os sentidos que as participantes expressaram a partir da temática proposta.

As dificuldades relacionaram-se aos aspectos burocráticos de início da pesquisa, ao momento da coleta das informações, pois não havia um local apropriado para a realização das entrevistas, sendo realizadas na própria enfermaria, adotando, portanto, o máximo cuidado para proteger as informantes sem prejuízo do alcance das respostas a que o estudo se propunha. Esperávamos para iniciar, quando havia menos pessoas na enfermaria. Por vezes foi necessário interromper, diante do choro do bebê, necessidade de amamentar, troca de fralda, ou quando entrava na enfermaria um dos membros da equipe de saúde, de enfermagem ou um familiar. Apontar as dificuldades é fator importante na coleta das informações, pois nem sempre o local idealizado é possível de ser conseguido, porém a adaptação do pesquisador resulta em sucesso da entrevista.

A entrevista possibilita melhor apreender os pontos de vista dos sujeitos entrevistados com um planejamento relativamente aberto, do que em uma entrevista padronizada ou com um questionário ${ }^{(6)}$. A entrevista capta idéias, crenças, maneiras de pensar, opiniões, sentimentos, maneiras de sentir, de atuar, comportamentos presentes e futuros, sendo um instrumento privilegiado de coleta de informações ${ }^{(5)}$.

$\mathrm{O}$ estudo respeitou os princípios éticos de pesquisa envolvendo seres humanos, conforme a Resolução 196/96 do Conselho Nacional de Saúde, o qual oferece diretrizes e normas para todo e qualquer tipo de pesquisa em saúde que envolve seres humanos ${ }^{(7)}$. Seguindo os princípios éticos foi elaborado o Termo de Consentimento Livre e Esclarecido, expondo todos os procedimentos com cada sujeito, de modo que todos os participantes assinaram de livre concordância. Foram observados os aspectos de zelo ético ao manter sigilo das informações e anonimato dos informantes. O projeto foi aprovado pelo Comitê de Ética e Pesquisa do Hospital Pequeno Príncipe-HPP sob n ${ }^{\circ}$ 0310-06.

\section{ANÁLISE DAS INFORMAÇÕES}

A amostra foi de 11 púerperas primigestas, com faixa-etária entre 20 e 30 anos. As entrevistas foram 
realizadas entre o $1^{\circ}$ e $4^{\circ}$ dia pós-parto, sendo que a média ficou no primeiro dia pós-parto. Entendemos que esse período ainda é um momento de euforia após o parto, mas é o momento em que a mulher está vivenciando os primeiros contatos com o bebê e já consegue demonstrar as percepções, emoções e surpresa de ser mãe pela primeira vez.
O Quadro 1 demonstra o perfil das puérperas primigestas apreendido durante as entrevistas. Dez mulheres são casadas e uma é solteira. Há predomínio do ensino médio completo e superior completo. A religião de maior incidência é evangélica, seguida da católica. A maioria não tem ocupação fora do lar. Os nomes foram escolhidos pelas próprias puérperas.

Quadro 1 - Distribuição da amostra de acordo com idade, estado civil, escolaridade, religião e ocupação. Curitiba, 2006

\begin{tabular}{|lccccc|}
\hline \multicolumn{1}{|c}{ Nome } & Idade & Estado Civil & Escolaridade & Religião & Ocupação \\
\hline 1. Copo de Leite & 21 & Casada & Superior C. & Católica & Do lar \\
2. Violeta & 25 & Solteira & Ensino Médio C. & Católica & Do lar \\
3. Rosa & 20 & Casada & Ensino Médio C. & Evangélica & Vendedora \\
4. Paty & 25 & Casada & Ensino Médio C. & Evangélica & Autônoma \\
5. Lirio & 30 & Casada & Ensino Médio C. & Católica & Ass.Financ. \\
6. Katy & 23 & Casada & Ensino Médio C. & Evangélica & Do lar \\
7. Paula & 23 & Casada & Ensino Médio C. & Nenhuma & Do lar \\
8. Maria & 23 & Casada & Ensino Fund. Inc. & Evangélica & Do lar \\
9. Mariana & 24 & Casada & Ensino Médio C. & Testemunha de Jeová & Recepcionista \\
10. Renata & 27 & Casada & Ensino Médio C. & Evangélica & Do lar \\
11. Alga Amarela & 29 & Casada & Superior C. & Católica & Do lar \\
\hline
\end{tabular}

Fonte: Maternidade Filantrópica de Curitiba (2006).

Entre as entrevistadas, $63.6 \%$ tiveram alguma intercorrência no pré-natal, estando relacionada a ganho de peso excessivo, sangramento, secreção vaginal, infecção urinária, náuseas, vômitos e trabalho de parto prematuro. Ao serem questionadas sobre o planejamento da gestação, 6 (54.6\%) referiram não ter planejado e 5 (45.4\%) informaram ter planejado a gravidez.

A análise qualitativa iniciou com a transcrição na íntegra dos depoimentos, com leitura exaustiva para buscar apreender a significação e impregnar-se do seu conteúdo. Essa fase exigiu dos pesquisadores mergulhar profundamente nas informações, lendo e relendo para compreender as reais significações. É uma fase árdua, pois, exige criatividade, dinamismo, sempre tendo em mente os objetivos da pesquisa e a questão norteadora para subsidiar a análise e atingir as unidades de contexto e significação. A análise utilizou as etapas de análise de conteúdo temática ${ }^{(8)}$.

Pré-análise que consiste na primeira etapa do processo de análise de conteúdo temática, em que diante do material obtido iniciaram-se as leituras para a elaboração de indicadores que orientaram a interpretação final. Após a transcrição das entrevistas, os pesquisadores, de posse de todos os discursos, iniciaram a primeira aproximação para a apreensão das significações do ser puérpera primigesta com relação à vivência do papel materno. Cada discurso foi analisado separadamente, para após ser englobado no todo. Essa etapa preparou a etapa subseqüente, pois ao ler os textos os pesquisadores já iniciaram a categorização.

Exploração do material. Nessa etapa abstraímos as categorias e subcategorias. Essa é a fase de codificação em que transformam-se os dados brutos visando alcançar o núcleo de compreensão do texto. A categorização permitiu que cada elemento estivesse em apenas um grupo decorrente da categoria escolhida. Foi possível fazer recortes do texto, para delimitar o contexto de compreensão, chegando às Unidades de Contexto. Uma vez identificadas as Unidades de Contexto apreendemos as Unidades de Significação.

No Quadro 2 a seguir, retratamos as categorias apreendidas, nas quais os discursos são apresentados com uma designação escolhida pelas próprias participantes desse estudo, seguidas da idade (a exemplo, Violeta, 25 anos).

Na Unidade de Contexto Gravidez: uma trajetória de aceitação e expectativa, os discursos revelam sobre a Unidade de Significação, Sentimentos 
Quadro 2: Representação das Unidades de Contexto e Unidades de Significação apreendidas. Curitiba, 2006

\begin{tabular}{|l|l|}
\hline \multicolumn{1}{|c|}{$\begin{array}{c}\text { Unidades de } \\
\text { Contexto }\end{array}$} & Unidades de Significação \\
\hline $\begin{array}{l}\text { A. Gravidez: uma } \\
\text { trajetória de } \\
\text { aceitação e } \\
\text { expectativa }\end{array}$ & $\begin{array}{l}\text { 1. Sentimentos de ser mãe pela } \\
\text { primeira vez. } \\
\text { 2. O envolvimento familiar diante } \\
\text { da primeira gestação. }\end{array}$ \\
\hline $\begin{array}{l}\text { B. } \text { Parto: concluindo } \\
\text { uma caminhada }\end{array}$ & $\begin{array}{l}\text { 3. O parto como ponto de início } \\
\text { do novo papel de mãe. } \\
\text { 4. A vivência do parto como } \\
\text { experiência singular. }\end{array}$ \\
\hline $\begin{array}{l}\text { C. } \text { O período } \\
\text { puerperal: } \\
\text { enfrentando novos } \\
\text { papéis }\end{array}$ & $\begin{array}{l}\text { 5. Alterações do cotidiano: o } \\
\text { cuidado do bebê. } \\
\text { 6. Apontando estratégias para a } \\
\text { adaptação ao papel materno. } \\
\text { 7. Rede de apoio suportivo na fase } \\
\text { de transição ao papel materno. }\end{array}$ \\
\hline $\begin{array}{l}\text { D. Ações da } \\
\text { enfermagem junto } \\
\text { as puérperas }\end{array}$ & $\begin{array}{l}\text { 8. Percepção do cuidado } \\
\text { desenvolvido pela enfermagem. }\end{array}$ \\
\hline
\end{tabular}

de ser mãe pela primeira vez, em que as púerperas primigestas afirmam que é um momento de felicidade, emoção, ansiedade, expectativa, sem explicação, uma coisa única, prazerosa, mágica, indescritível, maravilhosa, angelical, uma benção. Os sentimentos não variam de acordo com a idade da mãe e são vivenciados na mesma intensidade:

Bom, não tem palavras para explicar o que eu estou sentido agora, mas é uma felicidade imensa, porque filho é tudo na vida da gente né. Desde que está sendo gerado ali na sua barriga é uma coisa assim, sei lá, não dá para explicar. Vocês me pegaram sem palavras (Copo de Leite, 21 anos).

[...] ser mãe pela primeira vez, ah! é bom é gostoso, é, nossa, tudo de bom! O que você lembrar nesse dia de bom está relacionado ao fato de ser mãe, pode comparar, essa coisa é boa, então compara com isso sabe, o fato de você ser mãe pela primeira vez, eu pelo menos sinto assim (Violeta, 25 anos).

Ah! É maravilhoso ser mãe, porque é a realização de qualquer mulher ser mãe, assim (Paty, 25 anos).

Foi maravilhoso, algo assim gostoso. Você sabe que agora alguém depende de você, alguém depende para você dar carinho, que você vai ficar ali é [...]. Olhando, babando. É tão bom, dá um sentido diferente (Lírio, 30 anos).

[...] é uma alegria. Muito bom! Uma alegria assim, sabe que ele é bem vindo de mim, que ele é muito bem vindo na minha casa, na minha família (Renata, 27 anos).

A segunda Unidade de Significação, $O$ envolvimento familiar diante da primeira gestação, foi referido por algumas púerperas primigestas como um momento difícil e de medo para compartilhar a notícia da gravidez com os pais. As reações da família foram de nervosismo, raiva, desespero, situações de conflito, revolta, susto. Embora a maioria referiu ser casada, essa união é consensual, gerando insegurança, instabilidade ao relacionamento conjugal. $\mathrm{O}$ medo de compartilhar com os pais a notícia da gravidez denota que a união não tem a plena aceitação da família. Os depoimentos apontam a revolta dos pais ao saberem da gravidez, principalmente quando a relação com o companheiro não era estável. Alguns pais reagiram expulsando a filha de casa.

A rede de suporte é um fator significativo nessa vivência nova e transformadora. A família, como toda instituição social, apresenta aspectos positivos, como núcleo afetivo, de apoio e solidariedade. Mas, em contrapartida, apresenta igualmente aspectos negativos, como a imposição de regras e objetivos rígidos. A primeira gestação torna-se, muitas vezes, elemento gerador de conflitos e ambiguiidades ${ }^{(9)}$ :

[...] eu fui contar depois de três meses, e ela [sua mãe] ficou desesperada, só faltou me esganar, mas agora [é] vovó coruja. Ficou bem brava, mas agora o primeiro neto das duas avós, mas falou um monte que eu não me cuidava, e isso, que aquilo, mas a minha mãe não esquenta, não (Rosa, 20 anos).

Quando fiquei sabendo que estava grávida, eu estava na casa da minha mãe. Nós ainda estávamos para morar juntos, estava meio junto, eu parava mais na casa dele do que em casa, mas daí, quando eu soube, fiquei feliz com a gravidez. Mas, eu fiquei um pouco assustada por saber da reação da minha mãe de me expulsar de casa, e não deu outra (Paula, 23 anos).

Quando eu fiquei sabendo foi um desespero, meu 
marido adorou, na época era namorado, agora é marido. Eu chorei, chorei, chorei, aí o medo de contar para a minha mãe, Deus me livre (Rosa, 20 anos).

É possível apreender sentimentos ambivalentes, com envolvimento familiar significativo durante o processo gravídico-puerperal. Percebemos que a família sente-se feliz com a gravidez quando há a aceitação, suscita choro de emoção, cuidados e atenção aumentados do marido e a participação dos avós nesse processo. Quando a gestação é planejada a reação dos familiares é de felicidade, alegria, oferecendo maior suporte emocional à mulher. $\mathrm{O}$ tempo decorrido entre o conhecimento da gravidez e a aceitação pela família gera insatisfação para as mães que se sentem desprotegidas:

A minha gravidez foi ótima, bem tranqüila, bem calma, tirando os primeiros três meses, depois que eu contei para a minha mãe, e dai ela começou a ir nas consultas comigo, pois o meu marido trabalhava, trabalha ainda, dai era mais difícil (Rosa, 20 anos).

Não é o primeiro neto da minha família, a minha mãe já tem três netos, mas mesmo assim ela não é daqui de Curitiba, ela é de outra cidade. Mas, mesmo assim já veio ontem, cedo, quando soube. Está lá na minha casa me esperando e a minha sogra também. Estão todo mundo bem feliz, graças a Deus (Paty, 25 anos).

[...] fiquei feliz e o meи marido então, mais feliz. Eu já esperava porque já planejava, mas ele ficou mais feliz, porque não imaginou que já ia engravidar. Não demorou nem alguns dias já engravidei, e ele ficou feliz. Quando ficou sabendo que era um menino ficou mais feliz (Katy, 23 anos).

Na Unidade de Contexto Parto: concluindo uma caminhada, os depoimentos revelam sobre a Unidade de Significação $O$ parto como ponto de início do novo papel de mãe, as puérperas afirmam estarem preparadas para o parto, que é um momento prazeroso. Elas conseguem colaborar, pensam na 'carinha' do bebê, é o querer sentir a plenitude de ser mãe e ter a oportunidade de ser mãe por meio do parto normal. Referem emoções na hora do parto, como de dever cumprido, coragem, nervosismo, medo. Passar pela experiência do parto normal, torna a mulher completa:
Na hora do parto, quando o bebê estava nascendo [...] você não tem força, mas você arranja. Você quer que ele nasça, você não tem força, mas você colabora com o parto, é muito gostoso (Violeta, 25 anos).

Desde o começo eu estava falando para o meu marido que queria parto normal. Eu queria sentir. Já que é ser mãe, tem que ser mãe completa (Lírio, 30 anos).

[...] quando eu cheguei aqui no hospital eu não tinha dilatação, nada porque o meu parto foi induzido tudo, mas até o fim eu lutei para que fosse normal. Na hora, a gente sofre, grita, berra, esperneia, não agüenta, mas eu falei: não, eu tenho que ser mãe por inteiro, pensei nisso e, assim que tinha que ser (Lírio, 30 anos).

O parto foi, vamos dizer assim, eu digo que é um momento que Deus faz com que a gente fique meio...Acredite ou não acredite, você está lá e diz: eu vou ter um bebê. A primeira vez em que eu vi ele, meu Deus, eu tenho um filho, ele está aqui, eu chorei de emoção (Alga amarela, 29 anos).

Na Unidade de Significação $A$ vivência do parto como experiência singular foi possível apreender a experiência singular vivenciada por cada mulher no momento do parto. A mulher externa seus sentimentos, suas emoções, os medos, as suas crenças, as estratégias utilizadas para amenizar os desconfortos do momento da parturição. A singularidade e a particularidade suscitam que cada mulher deve ser cuidada de acordo com suas necessidades, ou seja, o cuidado individual, com paciência, responsabilidade, considerando seus sentimentos, valores e respeitando suas limitações. O nascimento é um rito de passagem que carrega consigo condições especiais, pois é um momento marcante da vida que evoca atos diferenciados e deve ser envolto de cuidados especiais ${ }^{(10)}$ :

[...] eu fiquei muito assustada. Sei que a dor assim foi algo realmente super incômodo, e a dor é terrivel mesmo. Eu achei que foi bem incômodo o processo de dilatação, trabalho de parto. Ficar aguardando as dores, ali, é terrivel mesmo, insuportável, mas deu tudo certinho (Mariana, 24 anos).

Na hora do parto [...] na verdade foi muito [...]. 
Foi bem complicado, bem. Sofri bastante, rompeu a bolsa, mas eu não tinha dilatação. Entrei no hospital às doze, onze horas, sem nada de dilatação. Aí eu fiquei até, eu fui ter ele sete e vinte da manhã. A bolsa rompeu em casa, daí eu vim para cá e eles colocaram o soro, mas eu não evolui e ainda consegui ganhar normal, por Deus, sem ponto, nada (Paty, 25 anos).

O meu parto foi tudo bem, foi tudo ótimo! O meu parto, graças a Deus, Deus colocou a mão, foi rapidinho e eu nem vi. Não tomei nem anestesia para tirar a dor, nada. Eu não queria cesariana, eu queria parto normal. Mas que nem falei, eu estava pedindo a Deus para ser assim rápido, para mim não sofrer muito, não ficar muito no hospital com dor. E foi rapidinho (Maria, 23 anos).

Na Unidade de Contexto O período puerperal: enfrentando novos papéis e na Unidade de Significação Alterações do cotidiano: o cuidado do bebê, os discursos revelam significativas mudanças no cotidiano familiar para o cuidado do bebê. Enfatizam que é serviço dobrado, é trabalhoso, com grandes preocupações, pois ocorre uma reviravolta na rotina familiar, maior compromisso, as pessoas necessitam mudar ou abdicar de certas rotinas, são impostas limitações, responsabilidades, vivências de novas situações. O puerpério é um período no qual a mulher passa por profundas alterações físicas, psicomotoras e sociais, quando ocorrem transformações anatômicas e funcionais necessárias ao retorno do organismo materno às condições não-gravídicas ${ }^{(11)}$.

Além disso, a mulher precisa adaptar-se a seu filho e a seu papel de mãe. Ela se sente responsável pela sobrevivência do filho, mas em especial a primípara sente-se insegura em relação aos cuidados do bebê. A transição ao papel materno é explícita quando as mães referem que muda tudo, em uma amplitude de difícil explicação, pois vivenciam diferentes demandas em um único momento, aquele que a partir do nascimento tornase um período de profundas modificações configurando a entrada ao papel materno. Pelas expressões, este período está apenas iniciando, não tem um delimitador de seu término.

Tornar-se mãe e pai gera um período de mudanças e instabilidades para a mulher e o homem que decidem ter filhos ${ }^{(12)}$ :

Ah! Mudou tudo, mudou tudo! Você deita preocupada, você levanta preocupada, você não dorme mais, você só cochila, você escuta qualquer coisa diferente você já acorda, é igual a um despertador! (Copo de leite, 21 anos).

[...] agora é serviço dobrado, é tudo dobrado. Vai sair, não tem com quem deixar, você não dorme mais até mais tarde, tem com o que se preocupar [...]. Me vejo com um monte de trabalho, só trabalho daqui para frente, trabalho, trabalho $e$ preocupação! (Copo de leite, 21 anos).

Acho que muda muita coisa na vida da mãe. Ela [a criança] muda tudo, ela faz uma reviravolta. Eu não sei ao certo o que muda, daí só com o tempo que a gente vai saber (Copo de leite, 21 anos).

Muda tudo praticamente, tudo! Antes, que nem se eu quisesse dormir até tal hora, dormiria: ai hoje, não vou fazer almoço, hoje não vou fazer janta, não tinha aquele compromisso. Agora ele depende de mim totalmente. Então, quando ele tiver maior e eu tiver trabalhando, vou ter um compromisso, direto para casa, pois tem gente esperando. Tem que fazer uma janta, tem roupa dele no canto para lavar, e coisas assim, então muda tudo! (Violeta, 25 anos).

Mudou, que eu vou ter que ser outra pessoa. Vou ter que me organizar, ser mais responsável. É vida nova! Ela vai trazer muita alegria para a gente, vai trazer novas situações na vida, novas alegrias, novas preocupações (Mariana, 24 anos).

Ainda, nos discursos, foi possível apreender que a mulher muda emocionalmente, pois começa a agir com a emoção e não com a razão. As questões de companhia são abordadas, a mulher não se vê mais sozinha, suscita pensamentos de não se ver mais como antes da gestação, pois agora tem uma família. As mulheres relataram que a experiência significa felicidade, ser mãe significa uma nova experiência. A maternidade traz mudanças fundamentais para a vida da mulher e da família. A gravidez se configura como uma nova fase da vida e uma experiência marcante envolvendo a mulher em sua totalidade $^{(13)}$ :

Já mudou tudo, já mudou todo o meu lado emocional. Agora eu só penso mais no emocional e não racional como eu pensava antes (Lírio, 30 anos). 
Agora, imagina, não sou mais sozinha. Antigamente eu era aquela mulher independente que só pensava no próprio umbigo, agora não (Lírio, 30 anos).

Não me vejo mais como antes. Já na maternidade eu não me via como antes. Eu era aquela mulher que liderava uma chefia, mandava, incomodava e aí com a maternidade eu baixei o ritmo, fiquei um pouco mais emotiva, sentimental. E eu tenho certeza que isso, na minha vida, ela veio para isso, me dar sentido emocional na minha vida, não pensar tanto assim, nessa loucura, dar mais valor a essa coisa humana, a emoção que antes não dava (Lírio, 30 anos).

Ser mãe significa uma nova experiência. Assim, agora eu vou dar mais valor para a minha mãe, porque é muito trabalho cuidar de um nenê. Ele chora, chora e a gente não sabe o que tem aí é difícil (Rosa, 20 anos).

A Unidade de Significação Apontando estratégias para a adaptação ao papel materno, fez emergir, por meio dos depoimentos, as estratégias que as puérperas primigestas utilizam para facilitar a adaptação ao papel materno, sendo elas variadas, de acordo com as experiências individuais de cada uma. É possível perceber dedicação, organização, execução do papel de mãe, fazer tudo, curtir a relação, não querer se preocupar, diminuir o ritmo, ficar em casa, fazer o melhor de si, voltar toda a atenção para o bebê, procurar acompanhamento médico, usar conhecimentos adquiridos em relação a cuidados com bebê, fazer cada vez melhor.

Para promover a adaptação à maternidade os pais precisam assumir comportamentos e habilidades para lidar com as mudanças e com o desequilíbrio da nova etapa. Os pais devem explorar seu relacionamento com o bebê e redefinir as relações entre eles mesmos, devem adaptar suas próprias vidas com o bebê $\hat{e}^{(12)}$.

[...] eu vou ter que fazer o papel de mãe, dar o coração e fazer de tudo (Copo de leite, 21 anos).

[...] agora eu não quero me preocupar, quero diminuir meu ritmo. Eu quero depois voltar a trabalhar, mas eu não penso agora. Eu quero curtir os meses que eu tenho em casa, eu quero curtir, eu quero ser mãe (Lírio, 30 anos).
Bem, a princípio, enquanto eu tiver em casa, vai seguir o curso normal. Nos primeiros 10 dias, eu vou levar ela no postinho, no caso, para tomar vacina e tudo (Mariana, 24 anos).

[...] procurar sempre estar em acompanhamento médico, sempre que possível, sempre que necessário também (Mariana, 24 anos).

Ah! Do meu ponto de vista, mesmo, eu tenho que dedicar a minha vida para ela, para ela e meu esposo, que são as duas minhas vidas. Do meu ponto de vista, ela é tudo para mim (Maria, 23 anos).

Na Unidade de Significação Rede de apoio suportivo na fase de transição ao papel materno, foi possível desvelar que as puérperas primigestas, apontam principalmente a mãe como apoio suportivo mais significativo, para auxiliar no cuidado com a casa e com o bebê. Com a chegada do bebê, o ambiente familiar sofre mudanças e mobilizações, alteram-se os horários, a estrutura física e a organização funcional da casa. Em função disso, dispor de uma rede de suporte social é imprescindível para as mães e famílias, já que as tarefas e responsabilidades se multiplicam nessa fase permeada de ajustamentos ${ }^{(14)}$ :

[...] minha mãe, tanto que ela já veio aqui hoje. Na primeira vez, eu estava muito fraca, nem consegui dar banho nele. Ela já foi dando e já foi, sabe, e vai ser ela mesmo (Violeta, 21 anos).

[...] a minha mãe, mãe coruja, pai coruja, irmã coruja. Nossa, tenho irmão, a gente é muito unidos em casa, então o tempo inteiro, todo mundo, eu mesmo, meu marido todo mundo. Com isso aí eu nem me preocupo, tanto agora, como depois (Lírio, 30 anos).

[...] as minhas irmãs, minha mãe, meus irmãos. Tem bastante gente, o marido. Ajuda não vai faltar (Paula, 23 anos).

[...] a minha mãe, familiares, amigos, todos. Tem bastante ajuda, ela tem bastante ajuda (Mariana, 24 anos).

Na Unidade de Contexto Ações da enfermagem junto às puérperas, emergiu a Unidade de Significação Percepção do cuidado 
desenvolvido pela enfermagem, a qual possibilitou apreender entre as puérperas primigestas, que a enfermagem necessita ser compreensiva, se dedicar mais, falar uma linguagem compreensível, fazer o cuidado da alma, ter noção do que está fazendo, ter personalidade, gostar do que faz, fazer o papel da enfermagem. As ações realizadas pela equipe de enfermagem às mulheres fogem, muitas vezes da realidade social e simbólica das mesmas, não atingindo assim, o alvo ${ }^{(14)}$.

O profissional de enfermagem precisa estar preparado para cuidar das mulheres, o que inclui a habilidade para comunica-se e implementar ações de educação em saúde ${ }^{(15)}$. A equipe de enfermagem necessita compreender e acreditar na sua importância como orientadora, realizando um trabalho compromissado, sistematizado e garantindo, assim, a qualidade da assistência ${ }^{(15)}$ :

Ah, em primeiro lugar, se eles se formam em enfermeiros, eles têm que estar ciente do que vão enfrentar pela frente. Eu acho que eles têm que ser compreensivo, eles têm que se dedicar mais. E outra, eles têm que entender o que o paciente está sentindo, não o que eles querem fazer. Já se formam para isso, então eles têm que saber o que eles estão fazendo, se ele têm que falar uma coisa. Eu acho que se um enfermeiro fala uma coisa, todos têm que concordar com o que aquele um está falando, todos têm que ter uma noção ali (Copo de leite, 21 anos).

[...] você não vê que fazem [o cuidado] assim da alma, que faz com vontade, com a vocação, que estudou, pois quando você estuda uma coisa você estuda porque gosta, porque você ama, não porque é obrigado a estudar. Eu acho assim que os enfermeiros e enfermeiras têm que pensar melhor no que estão fazendo. Eles acham, as enfermeiras acham, que só porque têm o diploma na mão, acha que tudo o que eles falam está valendo, e não é (Copo de leite, 21 anos).

Bom, a princípio tem que ter noção. Eu acho assim que na hora que você está nervosa, você precisa de uma pessoa conversando do teu lado. E na hora do pega pra capá mesmo, porque as outras sempre diziam, mas é assim mesmo, de longe falavam, mas é um aspecto que elas não podem fazer nada por aquela situação. É daquele jeito e pronto. É a natureza! (Alga amarela, 29 anos).
[...] o que a gente espera delas [enfermagem] é a personalidade mesmo. Você tem que gostar do que faz para também estar ajudando os outros, tem que gostar da profissão. Também, que não é fácil, porque é uma coisa que você lida com gente, com pessoas e lidar às vezes com maus costumes que as pessoas trazem. E tem que mostrar, na prática, como é corretamente, como é feita (Mariana, 24 anos).

A puérpera primigesta espera da enfermagem atenção, paciência, um cuidado especial, uma palavra diferente, estar junto, dar apoio e orientação nessa fase de adaptação ao papel materno, pois ela considera uma experiência única na sua vida. A mãe expõe seus temores, dúvidas, angústias, dificuldades, expectativas diante desse acontecimento nunca antes experenciado, ou seja, explicita que precisa de um vínculo de suporte confiável, em meio a tantas modificações e sensações novas:

Eu acho que também tem que ser atencioso. Não pode ser grosso, pois a gente já tá nervosa, já tá preocupada, ansiosa para ir embora e aí vem um chato, Deus me livre, não tem pessoa que agüenta! (Rosa, 20 anos).

[...] a gente sempre espera isso, um cuidado especial, uma palavra diferente, uma coisa assim, e isso faz a gente se sentir protegida (Paty, 25 anos).

[...] bom, o que a gente espera da enfermagem é todo apoio, e tudo que elas puderem passar para a gente. Dar apoio mesmo, e até emocionalmente. Elas, apoiando a gente desta forma está apoiando emocionalmente, que dá segurança para cuidar do bebê (Mariana, 24 anos).

[...] ficar conversando comigo, não arredar o pé, permanecer até quanto eu precisar, pois isso dá força, pois sem ajuda eu não conseguiria. Quando precisar elas [enfermagem] estar do meu lado, me ajudar, me acalmar na hora (Alga amarela, 29 anos).

Tratamento dos resultados obtidos $e$ interpretação. Após a conclusão das leituras e categorização, iniciamos a última etapa, de interpretação. Os resultados brutos foram tratados de maneira a serem significativos e válidos. $\mathrm{Na} 3^{\mathrm{a}}$ etapa da análise, realizamos inferências e os resultados, 
brutos foram interpretados, o que permitiu colocar em relevo as informações obtidas. A partir daí, são propostas inferências e realizam-se interpretações previstas em seu quadro teórico. A interpretação possibilitou ir além do texto, ir além da manifestação do dito. A interpretação tornou possível a fusão dos dados, voltada para o contexto do cuidado ${ }^{(16)}$. A inferência e interpretação foram reflexões do que aconteceu por trás do método de pesquisa.

Nesta fase foi possível apreender o significado da experiência de ser mãe pela primeira vez, vivenciada pelas puérperas primigestas em transição ao papel materno. A mulher vivencia uma variação de sentimentos que externaliza como um momento mágico, indescritível, angelical, de ansiedade, expectativa, sem explicação. Significa uma benção, felicidade, emoção, abrir mão de certas coisas. Também foram percebidos os sentimentos de medo da gestação, as dificuldades, a insegurança, e que a adaptação a essa nova fase leva algum tempo.

Percebemos a realização da mulher com a vivência do papel materno, o seu envolvimento e preocupação com o cuidado do bebê. A mulher se vê envolta em uma série de mudanças impostas pela gravidez e nascimento, e necessita redirecionar seu cotidiano e o da família para o cuidado ao novo membro que chega ao convívio familiar e que necessita de cuidados, de carinho e envolvimento.

Os discursos denotam que a rede de apoio nessa etapa é importante, pois a mulher experencia uma nova fase em sua vida, em que pode não estar preparada para superar. No puerpério ocorrem mudanças abruptas do corpo feminino, a fim de possibilitar o retorno às características pré-gravídicas, dificultando o cuidado do bebê e dos seus afazeres domésticos. A mulher conta, principalmente, com a mãe para ajudar nos cuidados com a casa e com o bebê. Uma adequada rede de suporte proporciona também apoio a alguns momentos particularmente diferenciados no decorrer da vida dos seres humanos como, por exemplo, os períodos de puerpério, parto e pós-parto, favorecendo às mulheres um maior controle do ambiente e autonomia bem como fornecendo esperança, apoio e proteção ${ }^{(17)}$.

A transição "é uma passagem, ou um movimento de um estado, condição ou lugar para o outro"(18:27). A mulher que antes era filha, esposa, trabalhadora, dona de casa, agora também é mãe, adquiriu um novo papel perante a sociedade na qual está inserida. Essa mudança tem um tempo cronológico para acontecer. Não é possível prorrogar esse momento, exceto em algumas exceções, pois no momento que o bebê está pronto, formado, ele nasce, a natureza se encarrega desse papel, às vezes com a ajuda da medicina.

A vivência do período gravídico-puerperal pode ser comparada à passagem de um lado para outro de uma ponte. A mulher inicia a trajetória como ser-mulhergestante e vislumbra o alcance no outro lado da ponte, o do papel materno tornando-se ser-mulher-puérpera. Transitar rumo ao papel materno expõe a mulher a vencer barreiras e a ter momentos agradáveis e felizes, simultaneamente ${ }^{(9)}$. Toda essa vivência, percorrida pela mulher durante o período gravídico-puerperal, nos faz refletir que a mulher tem que ser amparada e cuidada, para que a mesma construa pilares de sustentação a partir de suas próprias vivências para ,então, se adaptar ao novo papel, o papel materno.

Esse amparo deve ser realizado pelo enfermeiro, profissional que tem como objetivo o cuidar em todas as fases da vida. O cuidado desenvolvido pela enfermagem deve ter alguns atributos como interesse, respeito, solidariedade, paciência, conhecimento, empatia, responsabilidade e comprometimento, para que se possa atingir o alvo, o cuidado humano e solidário voltado à singularidade e especificidades de cada um.

Compreender as vivências da puérpera primigesta rumo ao papel materno é aspecto importante para a enfermagem neste campo de atuação, visto que a mulher necessita de amparo, pois nem sempre conta com quem dê suporte a ela nessa fase. A partir dessa percepção é possível traçar estratégias de cuidado transicional que propiciem uma melhor adaptação ao papel materno.

Algumas estratégias podem auxiliar o enfermeiro a facilitar a apropriação do papel materno, como atuar no cuidado direto a mulher, considerando-a como ser integral e único, cuidando de maneira individualizada, respeitando sua singularidade, crenças e valores, na medida em que não sejam prejudiciais à saúde da mulher e do bebê, ouvir suas indagações e valorizar seus depoimentos. O enfermeiro deve se colocar na posição de troca e não de detentor do saber, facilitar o contato da puérpera com a família, esposo e educá-la para a amamentação, os cuidados com o bebê e o planejamento familiar ${ }^{(19)}$.

Outra estratégia importante que pode facilitar a apropriação ao papel materno é que a mulher e o pai participem ativamente no nascimento da criança, e que a mãe tenha a oportunidade de ver e tocar o filho, o mais cedo possível, após o nascimento; auxiliar para que possa demonstrar as alegrias que um bebê pode 
trazer e estimular a autoconfiança da mãe para relaxar e aproveitar a presença do seu bebêt $\hat{e}^{(20)}$.

\section{CONSIDERAÇÕES FINAIS}

Após percorrer as etapas desse estudo, podemos compreender a vivência da puérpera primigesta rumo ao papel materno, seus sentimentos, realizações, medos, dificuldades, mudanças impostas pela chegada do bebê e o cuidado de enfermagem necessário nessa fase de transição.

Percebemos que a vivência transicional é súbita, pois não tem como adiar esse momento. O bebê nasce, necessita de cuidados e a mulher necessita se adaptar a essa nova fase, organizar seu cotidiano, continuar suas relações com o grupo no qual está inserida e assumir sua nova identidade perante a sociedade, a de ser mãe.

É preciso compreender que os assuntos relacionados à transição não podem ser associados apenas às questões biológicas, mas também às questões sociais, emocionais e psicológicas, pois a complexidade do fenômeno da transição não envolve apenas a mulher, mas sim toda sua rede de relacionamentos. Para minimizar as dificuldades que a maternidade traz, se faz necessário que a mulher construa suportes alicerçados em conhecimento, responsabilidade, criatividade, segurança, amor, carinho, compreensão e sincronismo, para o seu ajustamento à maternidade.

Nesse sentido, vale ressaltar a importância de que desde a graduação os acadêmicos de Enfermagem já tenham contato com assuntos dessa complexidade, para despertar atitudes de investigação, preocupação, zelo e senso crítico para ultrapassar o mero pensar tecnicista, fragmentado e restrito, para alcançar o seu objetivo, que é cuidar do ser humano em todas as fases da vida.

Fica evidente que cuidar de puérperas primigestas deve ser repensado por toda a equipe de saúde, com o resgaste de ações humanísticas, de solidariedade, empatia e compromisso.Elas devem permear o contexto de gestação, parto e puerpério, pois no momento que refletimos sobre estes aspectos observamos que a mulher tem necessidades de orientação, apoio e acolhimento para o seu ajustamento à maternidade. Assim, o cuidado transicional deve permear toda a trajetória, o processo de transição, desde sua entrada até a saída do serviço de saúde. Esse período é acompanhado e experenciado de forma compartilhada entre o enfermeiro e a puérpera primigesta, no qual se unem para alcançar o novo papel partilhando, dividindo, somando, a partir de cada particularidade, sem deixar de apropriar-se de seu respectivo papel.

Finalmente, pode-se afirmar que, o enfermeiro deve ser treinado, preparado para cuidar da puérpera primigesta e da sua família, de forma segura e humanizada, pois a maternidade é uma das fases mais significativas na vida da mulher. Ela merece um cuidado especial o qual deve englobar características como intuição, sensibilidade, dinamismo, respeito, percepção, compromisso, autonomia, julgamento clínico e conhecimento. Deve-se ultrapassar o fazer cotidiano e fisiológico, e permitir que o enfermeiro estabeleça uma conduta mais humanista e solidária. Essa preocupação tem que se iniciar ainda na formação dos futuros profissionais, repensar que tipo de cuidadores se quer formar e se está formando para o desempenho do cuidado transicional.

\section{REFERÊNCIAS}

1 Monteiro TMT, Silva LMS, Silva MVS. Reações de mães diante do nascimento de um filho prematuro. Cogitare Enferm. 2002 Jan/Jun;7(1):36-42.

2 Zagonel IPS. O cuidado humano transicional na trajetória de enfermagem. Rev Latino-am Enferm.1999 Jul;7(3): 2532 .

3 Maldonado MTP. Psicologia da gravidez. $14^{\mathrm{a}}$ ed, Petrópolis: Vozes; 1997.

4 Zagonel IPS, Martins M, Pereira KF, Athayde J. O cuidado humano diante da transição ao papel materno: vivências no puerpério Rev Eletron Enferm.[periódico na Internet]. $2003 \mathrm{Jul} / \mathrm{Dez}$ [acesso em 2007 Ago 10] 5(2):24-32. Disponível em: http://www.fen.ufg.br/revista

5 Minayo MCS. O desafio do conhecimento: pesquisa qualitativa em saúde. São Paulo: Hucitec-Abrasco; 2004.

6 Flick U. Uma introdução à pesquisa qualitativa. $2^{\mathrm{a}} \mathrm{ed}$. Porto Alegre: Bookman; 2004.

7 Ministério da Saúde (BR). Conselho Nacional de Saúde. Diretrizes e normas regulamentadoras de pesquisa envolvendo seres humano. Resolução nº 196, de 10 outubro de 1996. Brasília; 1996.

8 Bardin L. Análise de conteúdo. Rio de Janeiro: Edições $70 ; 1991$.

9 Machado MVP. A transição do ser adolescente puérpera ao papel materno sob o enfoque do cuidado de 
enfermagem [dissertação]. Curitiba (PR): Universidade Federal do Paraná; 2004.

10 Monticelli M. Nascimento como rito de passagem: abordagem para o cuidado às mulheres e recémnascidos. São Paulo: Robe; 1997.

11 Espiríto Santo LC, Berni NIO. Enfermagem em obstetrícia. In: Freitas F, Martins-Costa SH, Ramos JGL, Magalhães JÁ. et al. Rotinas em obstetrícia. Porto Alegre: Artmed; 2001.

12 Edwards LD. Adaptação à paternidade, maternidade In: Lowdermilk DL, Perry SE, Bobak IM. O cuidado de enfermagem materna. $5^{\text {a }}$ ed. Porto Alegre: Artmed; 2002.

13 Wall ML, Carraro TE. Reflexões sobre o programa Mãe Curitibana, a cliente mulher-mãe e a metodologia da assistência na prática do enfermeiro. Cogitare Enferm. $1999 \mathrm{Jul} / \mathrm{Dez} ; 4(2): 79-85$.

14 Stefanello J. A vivência do cuidado no puerpério: as mulheres construindo-se como mães [dissertação]. Ribeirão Preto (SP): Programa de Pós-Graduação em Saúde Pública: Universidade de São Paulo; 2005.

15 Bulhosa MS, Santos MG, Lunardi VL. Percepção de puérperas sobre o cuidado de enfermagem em unidade de alojamento conjunto. Cogitare Enferm. 2005 Jan/ Abr;10(1):42-7.

16 Zagonel IPS. O ser adolescente gestante em transição ex-sistindo: um enfoque de cuidar-pesquisar sob a ótica da enfermagem [tese]. Florianópolis (SC): Programa de Pós-Graduação em Enfermagem. Universidade Federal de Santa Catarina; 1998.

17 Baptista MN, Baptista ASD, Torres ECR. Associação entre suporte social, depressão e ansiedade em gestantes. Rev Psicol. 2006;7(1):39-48.

18 Machado MVP, Zagonel IPS. O processo de cuidar da adolescente que vivencia a transição ao papel materno. Cogitare Enferm. 2003 Jul/Dez;8(2):26-33.

19 Carraro TE. A mulher no período puerperal: uma visão possível. Texto Contexto Enferm. 1997 Jan/Abr;6(1):8491.

20 Ziegel EE. Enfermagem obstétrica. $7^{\mathrm{a}}$ ed. Rio de Janeiro: Interamericana; 1980. 